\title{
Monitoring of horizontal movements of high-rise buildings and tower transmitters by means of ground-based interferometric radar
}

\author{
M. Talich ${ }^{1 *}$ \\ ${ }^{1}$ The Czech Academy of Sciences, Institute of Information Theory and Automation, Prague, Czech Republic - \\ milan.talich@utia.cas.cz
}

KEY WORDS: Ground-based radar interferometry, Horizontal movements, Deformations, High-rise buildings, Tower transmitters

\begin{abstract}
:
The paper describes possibilities of the relatively new technics - ground based radar interferometry for precise determining of deformation of structures. Special focus on the horizontal movements of high-rise buildings and on the tower transmitters is presented. The technology of ground based radar interferometry can be used in practice to the contactless determination of deformations of such structures with accuracy up to $0.01 \mathrm{~mm}$ in real time. It is also possible to capture oscillations of the object with a frequency up to $50 \mathrm{~Hz}$ in real time. Deformations can be determined simultaneously in multiple places of the object, for example in the case of high-rise buildings it is possible to monitor the horizontal vibration of the whole object at its different height levels intervals of one or more meters. It is possible to detect and determine the compound oscillations that occur in some types of such buildings. This allows to obtain both overall and detailed information about the properties of the structure during its dynamic load e.g. by wind. Then prevent any damage or even disasters in these objects. In addition to the necessary theory basic principles of using radar interferometry for determining of deformation of structures are given. Practical examples of determining of horizontal movements of high-rise building and tower transmitter are also given. The IBIS-S interferometric radar of the Italian IDS manufacturer was used for the measurements.
\end{abstract}

\section{INTRODUCTION}

By looking for methods of some contactless observation and measurements of horizontal movements of the high-rise structures, we need to define other requirements for these methods as well. One of these requirements might be the ability to observe movements in real time for both, short and long time span. For example, in the case of high-rise buildings they are wind gusts. As well dynamically observe and measure frequencies and amplitudes of observed object's oscillation in range for example of $50 \mathrm{~Hz}$. Ability to determine the size of movements with accuracy in $0.01 \mathrm{~mm}$, because the size of the movements is usually in range from $0.1 \mathrm{~mm}$ to $100 \mathrm{~mm}$. Ability to simultaneously determine movements on multiple points of the observed object, so that is possible to get both, detail and whole information about movements of the structure during dynamic stress.

To all of these requirements fits the method of measurement based on principles of ground-based radar interferometry. The big capability of this method is the simultaneously measurement of multiple movements on multiple points on one observed object with range resolution at least of $0.75 \mathrm{~m}$. For example, on high-rise structure with high of $100 \mathrm{~m}$, we can simultaneously observe and measure roughly 100 points. To show the possibilities of the radar interferometry technology, this article will focus to determining of horizontal movements of two different object types. It will be measurement of horizontal movements of high-rise buildings and tower transmitters. The measurements are done by interferometry radar IBIS-S (IBISFS) of IDS - Ingegneria Dei Sistemi Company.

\section{PRINCIPLES OF USING RADAR INTERFEROMETRY}

Basic principles of radar interferometry with IBIS-S are described below. The IBIS-S products are based on two wellknown radar techniques:

1. Stepped Frequency Continuous Wave (SF-CW),

2. Differential interferometry.

\subsection{Stepped Frequency Continuous Wave}

The continuous stepped frequency wave serves to measure the distance from radar to observed object. It resolves the scenario in the range direction, detecting the position in range of different targets placed along the radar's line of sight. Microwave radiation is sent out in short high-power pulses and the distance to object is calculated from time correlation between sent and received signal. Utilizing this technology IBIS constructs a one-dimensional image called range profile. The illuminated area is divided into circular segments (range bins $=$ resolution cells) of constant distance from radar. All targets in a given segment contribute to the observed values (amplitude and phase) of the segment. The segments' width is called range resolution $\Delta R$. The distance from radar to target is calculated from formula:

$$
R_{0}=\frac{c T_{o}}{2},
$$

where $T_{0}$ is delay in response. The range resolution can be calculated from 


$$
\Delta R=\frac{c \tau}{2}
$$

where $\tau$ is pulse width. This means the radar is able to discern two distinct targets only if $\Delta t>\tau$ and thus $\Delta d>\Delta R$. Range resolution is limited by pulse width.

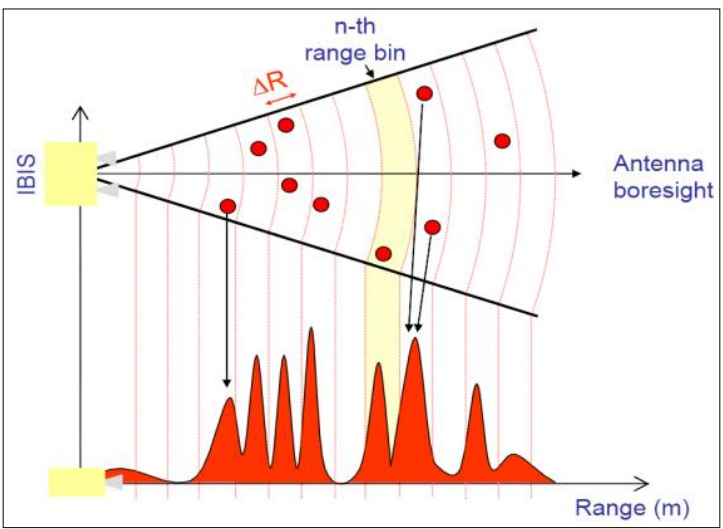

Figure 1. Range resolution concept (source: [IDS, 2011])

Figure 1 shows range resolution. $\mathrm{X}$ axis is distance from radar. The IBIS-S radar can distinguish targets only in one direction (in the line of sight). If there are more targets in the same range bin (single cell), these cannot be told apart and movements of individual targets are averaged. $\mathrm{Y}$ axis shows signal to noise ratio of received signal.

\subsection{Differential interferometry}

After resolving the scenario in the range direction and detecting the position in range of different targets placed along the radar's line of sight we can start to compute movements of individual targets by the differential interferometry method. In this case the range bins are obtaining individual targets and representing parts of observed object. This method uses differences in phase values about range bin from two (or more) acquisitions to determine their relative movement. The principle is shown on Figure 2. The computed movements $d$ are in the line of sight of the radar (LOS) direction. There is a limit value of movement $d_{\max }$ between two acquisitions caused by ambiguity of observed phase. For IBIS-S this maximum movement is $4.38 \mathrm{~mm}$.

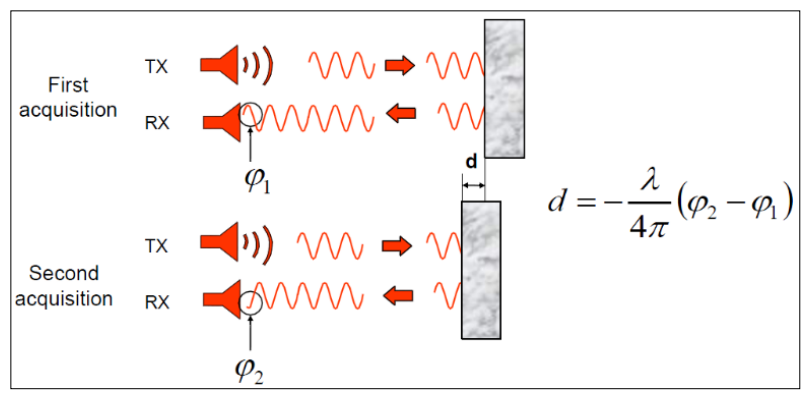

Figure 2. Differential interferometry principle (source: [IDS, 2011])

\subsection{Computing of real movements}

All movements are measured in line of sight. If the radar's line of sight is not parallel with expected direction of the movement then the real movement have to be computed from LOS movement by using the following formula $d=d R / \sin (\alpha)$, where $\sin (\alpha)=h / R$ and so $d=d R \cdot R / h$, see Figure 3. The situation of measurement is usually as in the Figure 3. The distance $R$ is measured by the radar, the horizontal distance from the object $h$ is necessary to determine with additional geodetic measurement.

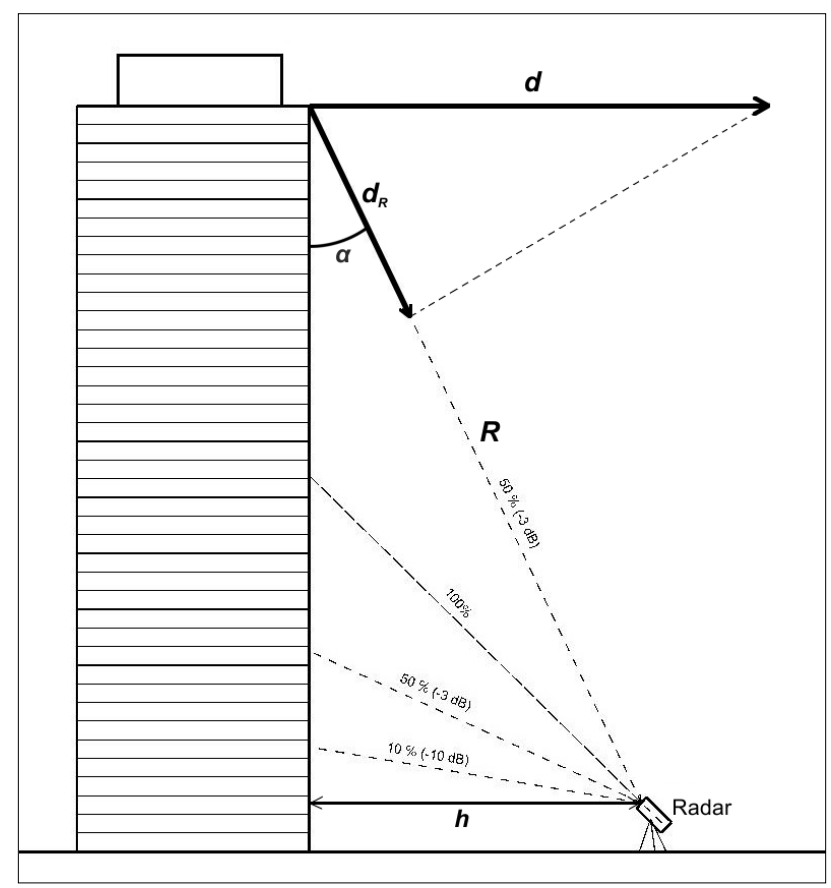

Figure 3. Line of sight movement $(d R)$ and real movement $(d)$

\subsection{Instrument characteristics}

All measurements presented in this contribution are done by interferometry radar IBIS-S (IBIS-FS) of IDS - Ingegneria Dei Sistemi company. IBIS-S is a terrestrial coherent radar interferometer [Gentile et al., 2010]. It works in microwave spectrum with frequency of $17.1-17.3 \mathrm{GHz}(\mathrm{Ku})$. The reflected radiation is recorded with sampling frequency from 10 to $200 \mathrm{~Hz}$. Maximum effective range is $1 \mathrm{~km}$. The standard deviation according to manufacturer is $0.01 \mathrm{~mm}$ under ideal conditions. The resolution is $0.75 \mathrm{~m}$ in range direction.

\section{EXAMPLES OF USING TECHNOLOGY IN PRACTICE}

Technology of the ground based radar interferometry can be successfully used to determine the deformation of a wide range of different types of objects. Very useful is the use of this technology for the determination of horizontal movements of various kinds of high-rise buildings. Two examples of specific use for these purposes will be shown below. Moreover, it is very common to use this technology for the determination of vertical deflections of metal or concrete bridges [Gentile, 2009, Lipták et al., 2014] and deformation of a variety of special objects such as for example floodgates.

\subsection{Monitoring horizontal movements of high-rise building}

An example of monitoring horizontal movements of high-rise building is shown on a high-rise City Tower building in Prague 4 - Pankrác [Talich et al., 2014a]. The building has 27 floors and 3 underground floors and is $109 \mathrm{~m}$ high.

Radar was placed on the windward side of the building to the west facade of the building. The wind speed was approximately 
5-7 $\mathrm{ms}^{-1}$. The wind direction was steady west. The positioning of standpoint is a compromise between the requirements for the distance between the radar and the object. With the increasing distance, the reflected signal strength and the maximum measurable sampling rate decrease.
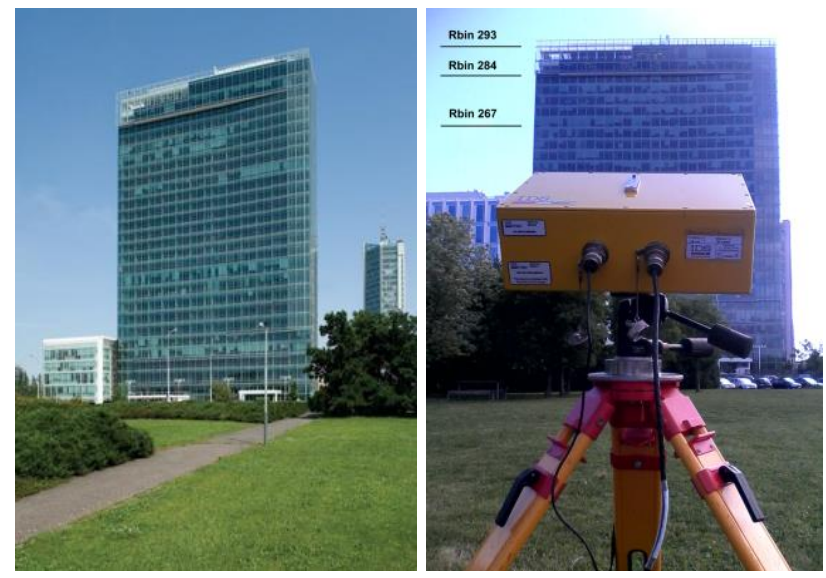

Figure 4. City Tower building in Prague 4 - Pankrác

Three strongest reflections were selected for the evaluation. These are uniformly distributed on the facade of the building as shown in Figure 4. Rbin 267 approximately in the middle of the facade, Rbin 284 overhangs of the last two floors, and Rbin 293 Roof Edge. As can be seen from Figure 4, a number of highquality reflections can be found on the facade of this sample object, and therefore there is no need to fit corner reflectors.

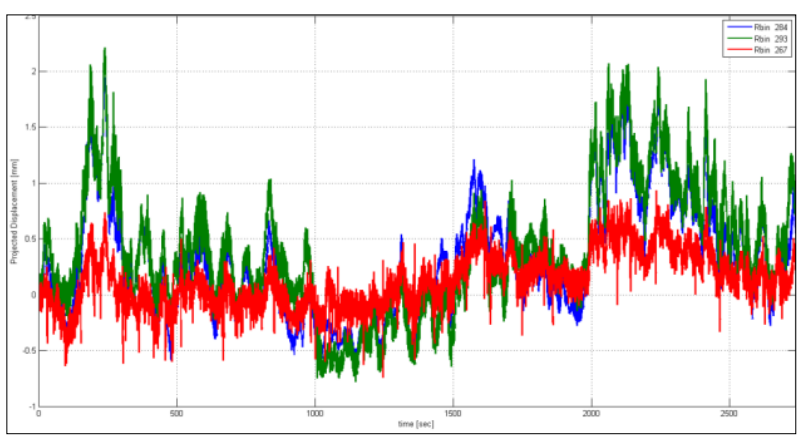

Figure 5. Horizontal movements of selected Rbins - for the entire measurement time

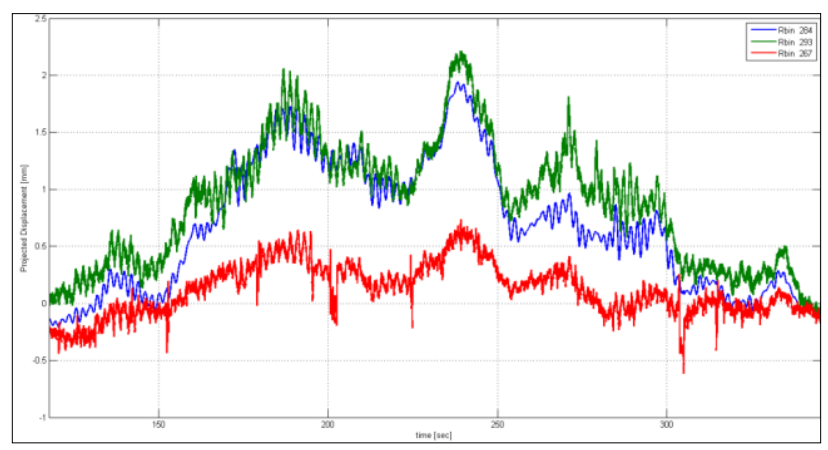

Figure 6. Horizontal movements of selected Rbins - detail

In Figures 5 and 6 there is a graph of horizontal movements of selected Rbins. There is a varying amplitude of oscillation, depending on the varying wind force. This is the so-called "motion of the grass stalk in the wind". The movement of the top of the building ranges from $+2.2 \mathrm{~mm}$ to $-0.6 \mathrm{~mm}$.

The measurement did not detect any interference with the oscillation of the movements. It can be assumed that the building is not equipped with a vibration damper or has not been running due such small movements. Another option is that the construction of the building is stiff and does not require damping.

The oscillation frequency of a building can be determined by frequency analysis or, from the frequency periodogram in Figure 7. The strongest frequency is $0.48 \mathrm{~Hz}$. Another significant frequency is $0.6 \mathrm{~Hz}$.

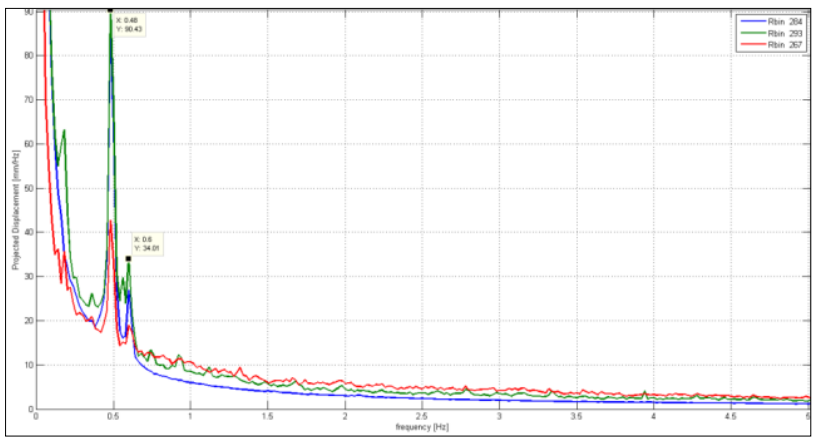

Figure 7. Periodogram frequency analysis of selected Rbins

\subsection{Monitoring horizontal movements of tower transmitters}

An example of monitoring horizontal movements of tower transmitters is shown on a Žižkov transmitter in Prague [Talich et al., 2014b], which is one of Prague's dominant and at the same time the tallest building $(216 \mathrm{~m})$ in the city. Base reinforced concrete plate with a diameter of $30 \mathrm{~m}$ and a thickness of $4 \mathrm{~m}$, is located at a depth of $15 \mathrm{~m}$ below the original surface. The vertical construction consists of three cylindrical steel tubes. The two adjacent tubes have a diameter of $4.8 \mathrm{~m}$ and reach a height of 134 meters. The main tube has a diameter of $6.4 \mathrm{~m}$, and passes into the antenna extension reaching to a height of $216 \mathrm{~m}$. Tubes are made of concentric steel pipes, with a $30 \mathrm{~cm}$ thick space to be poured with concrete. The project of the transmitter construction was calculated with a maximum horizontal displacement of the top of the tower of $1.20 \mathrm{~m}$. The vibration damper limits the displacement to a maximum of $12 \mathrm{~cm}$.

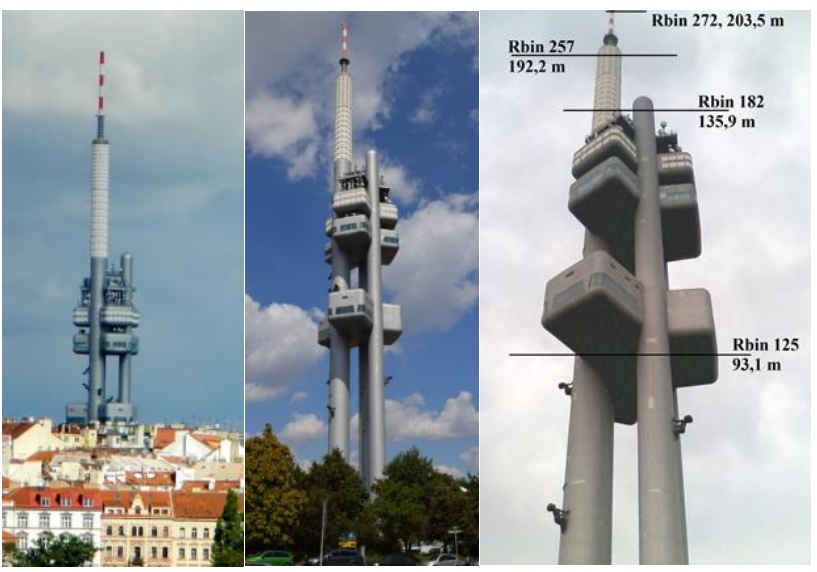

Figure 8. Tower transmitter Prague - Žižkov and selected Rbins 
The radar was located on the leeward side about $60 \mathrm{~m}$ from the transmitter. During the course of the measurement, the average wind was 5-9 $\mathrm{ms}^{-1}$. On the tube transmitters are significant sections of the joint, viewing platforms, restaurants, etc., which reflect the radar signal very well and are evenly distributed on the tubes. It is therefore advisable to select these significant links for evaluation, i.e. to determine their movements.

To evaluate the horizontal movements of the tower transmitter, the following high quality reflections were selected. The Rbin 125 is located below the first floor of the viewing platforms. The Rbin 182 shows the movement of the peaks of the shorter masts of the transmitter. The Rbin 257 shows movement at the top of the antenna extension and the Rbin 271 of the transmitter top.

The resulting horizontal movements of selected Rbins for the entire measurement time are shown in Figure 9. This graph shows high frequency and variable amplitude of the oscillation of the tower. Larger movements starting from the measurement time of about 550s are probably caused by the strengthening wind. The tower is deflected by the force of wind and vibrates in a tilted position. As with the high-rise building in the previous example, there is also the "motion of the grass stalk in the wind" effect. The resulting horizontal movements of the top of the transmitter ranges from $+8 \mathrm{~mm}$ to $-23 \mathrm{~mm}$ under wind of $5-9 \mathrm{~ms}^{-1}$.

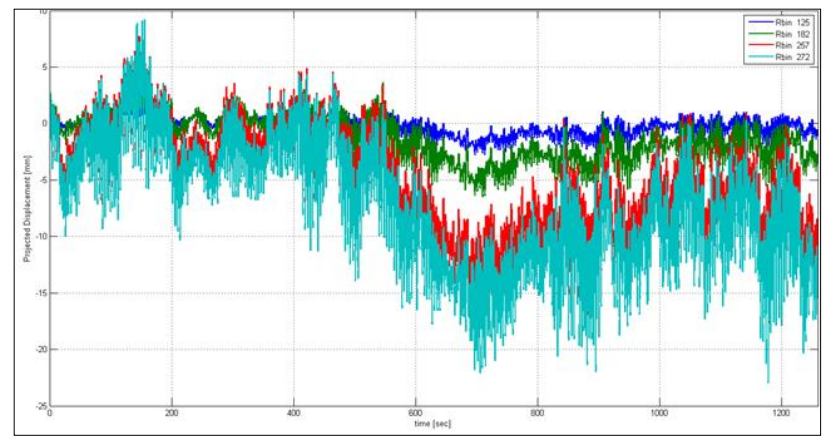

Figure 9. Horizontal movements of selected Rbins - for the entire measurement time

In a more detailed study of the oscillation of the tower in Figure 10 , the composite oscillation that is caused by the active vibration damper is recognizable. Oscillation of the tower is the sum of these two components.

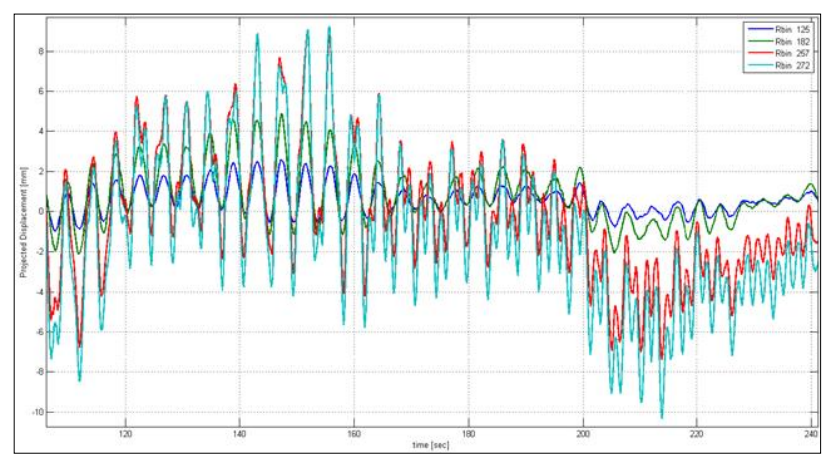

Figure 10. Detail of the composite oscillation

The frequency periodogram is shown in Figure 11. There are two main frequencies: $0.24 \mathrm{~Hz}$ and $0.56 \mathrm{~Hz}$.

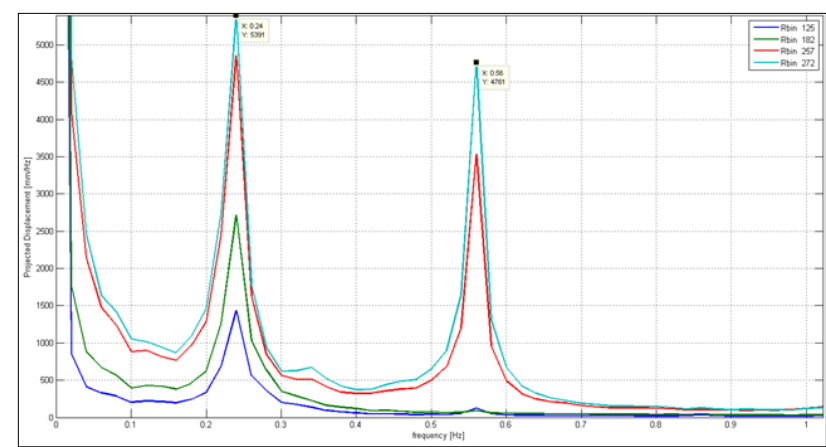

Figure 11. Periodogram frequency analysis of selected Rbins

\section{GENERAL PRINCIPLES OF USING TECHNOLOGY IN PRACTICE}

The purpose of the article is to describe possibilities of the relatively new technics - ground based radar interferometry for precise monitoring of horizontal movements of high-rise structures. An example of two different types of such structures has shown it. However, certain usage policies must be followed to successfully deploy this technique in practice. These are:

- Ground interferometry radar is sensor measuring only relative movements in its line of sight (LOS). The movements measured by the radar in the LOS direction are evaluated in the horizontal or vertical direction according to the assumed direction of the real movements based on the user's choice. If the direction of real motion of the object is different from the user's predicted direction, an erroneous evaluation that cannot be detected is made.

- Radar is not able to discern movement perpendicular to its line of sight (LOS).

- There is a maximum movement between two subsequent acquisitions that is possible to correctly determine. This value corresponds to phase difference $\Delta \varphi=2 \pi$. For example for IBIS-S this maximum movement is \pm 4.38 $\mathrm{mm}$ (for $\Delta R=0.75 \mathrm{~m}$ ). If this value is exceeded the resulting movement is incorrect. This error cannot be detected. The frequency of acquisition can be up to 200 $\mathrm{Hz}$, so it is possible to observe movements with speed up to $0.876 \mathrm{~ms}^{-1}$.

- It allows monitoring area of interest from distance up to $1 \mathrm{~km}$ without the need to install additional sensors or optical targets in case of good reflection of signal. In the other case is necessary to install additional corner reflectors.

- It is possible to simultaneously observe multiple points on the object. So it is possible to get both, detail and whole information about behaviour of the object.

- The movements are measured directly in real time.

- Observations are possible during both day and night and almost regardless of climatic conditions.

- The standard deviation of the movements determining is about $0.01 \mathrm{~mm}$ and mostly depends on the quality of reflected signal, i.e. size of the corner reflectors and the distance from radar. The basic verification of precision was done by field measuring known changes in lengths caused by the micrometer screw. The results are in appendix of this contribution. It was recognized that this technology could be used to determining of movements with precision in the range from $0.01 \mathrm{~mm}$ to $0.1 \mathrm{~mm}$. 
Next examples, advantages, limitations and possible applications are for example in [Owerko et al., 2012], [Pieraccini, 2013] and [Talich, 2017].

\section{CONCLUSIONS}

Presented technology of ground-based radar interferometry provides determining and monitoring of movements of many different structures and objects. Only because of the need to reduce this article, the results of other measured objects are not presented (e.g. horizontal transversal movements of flood-gate sides, vertical deflections of the concrete and metal bridge, horizontal movements of the water tower reservoir, factory chimneys or wind power plant pylons, etc.). Technology provides determining and monitoring of the movements of structures with high relative precision (up to $0.01 \mathrm{~mm}$ ) in real time simultaneously on multiple points of the observed object. From the results we can obtain new information about behaviour of some structure types. It is recommended to periodically repeat measurement with a certain interval to get information about observed object's behaviour depending on its senescence, external conditions or the season.

\section{ACKNOWLEDGEMENTS}

This work was partially supported by the Czech Science Foundation under the grant No. GA18-07247S and by the Ministry of Industry and Trade of the Czech Republic, project "Investigation of terrestrial InSAR efficiency for deformation analysis of hazardous objects and localities" grant No. FRTI4/436.

Every measurement was carried out within the project P-InSAR by employees of the Geodézie Ledeč nad Sázavou s.r.o surveying company.

\section{REFERENCES}

Gentile, C., 2009. Application of Radar Technology to Deflection Measurement and Dynamic Testing of Bridges. In: Radar Technology, ed.: Guy Kouemou, ISBN 978-953-307029-2, pp. 141-162, December 2009, INTECH, Croatia, DOI $10.5772 / 7178$

Gentile, C. and Bernardini, G., 2010. An interferometric radar for non-contact measurement of deflections on civil engineering structures: laboratory and full-scale tests. Structure and Infrastructure Engineering, 6(5), pp. 521-534, DOI $10.1080 / 15732470903068557$

IDS - Ingegneria Dei Sistemi S.p.A. Development Team, 2011. IBIS-S Training Course presentation, Pisa, 2011

Lipták, I., Erdélyi, J., Kyrinovič, P., Kopáčik, A., 2014. Monitoring of Bridge Dynamics by Radar Interferometry, In: INGEO 2014, 6th International Conference on Engineering Surveying, Prague 2014, pp. 211-216.

Owerko, T., Ortyl, Ł., Kocierz, R., Kuras, P., Salamak M., 2012. Investigation of displacements of road bridges under test loads using radar interferometry - Case study. In: Bridge Maintenance, Safety, Management, Resilience and Sustainability. Proceedings of the Sixth International IABMAS
Conference, Stresa, Lake Maggiore, Italy, 8-12 July 2012, pp. 181-188, ISBN: 978-041562124-3, DOI 10.1201/b12352-19

Pieraccini, M., 2013. Monitoring of Civil Infrastructures by Interferometric Radar: A Review. The Scientific World Journal, Hindawi Publishing Corporation, Volume 2013, Article ID 786961, 8 pages, http://dx.doi.org/10.1155/2013/786961

Talich M., 2017. Using Ground Radar Interferometry for Precise Determining of Deformation and Vertical Deflection of Structures. IOP Conference Series Earth and Environmental Science, 95(3):032021, DOI 10.1088/1755-1315/95/3/032021

Talich M., Glöckner, M. , Antoš, F. , Soukup, L., Havrlant, J., Böhm, O., Závrská, M., Šolc, J., 2014a. Verified technology of horizontal movements determination of high-rise buildings by means of terrestrial interferometric radar. (in the Czech language). ÚTIA, 2014, 20p., available from: http://www.pinsar.cz/file.php?id=UMTQ4MDQy (14 February 2018)

Talich M., Glöckner, M. , Antoš, F. , Soukup, L., Havrlant, J., Böhm, O., Závrská, M., Šolc, J., 2014b. Verified technology of horizontal movements determination of tower transmitters by means of terrestrial interferometric radar. (in the Czech language). ÚTIA, 2014, 22p., available from: http://www.pinsar.cz/file.php?id=xMTQ4MDM5 (14 February 2018)

\section{APPENDIX}

\section{Verification of precision determination of shifts by radar interferometry technology in field conditions}

The method of verification of radar interferometry is based on radar interferometric measurements of known changes in the length of the test base. For comparison with the precision of the classical geodetic methods, geodetic determinations of changes in lengths of the same test base can be made simultaneously by a precision total station.

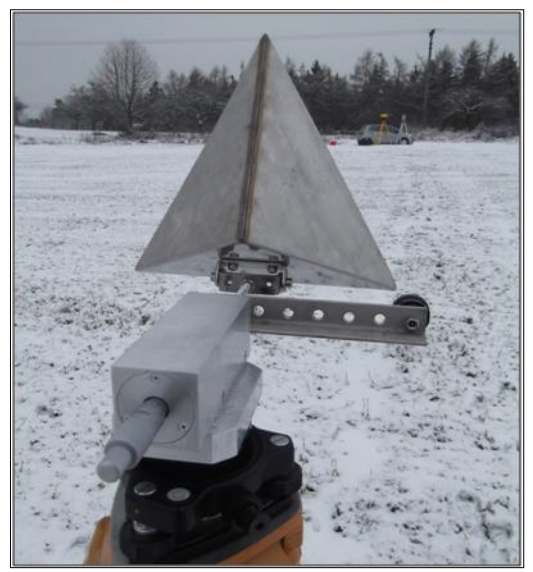

Figure 12. Micrometer screw with corner reflector and prism

Both devices will target to special micrometric device on which is placed a metal corner reflector for the radar and a glass prism for the total station. Both reflectors must be fastened together and attached to micrometric screw which can be slid with respect to the radar and the total station. The resolution of the micrometer screw must be at least $0.01 \mathrm{~mm}$. The construction of the micrometer device with a corner reflector and prism is shown in Figure 12. 
Testing can also be carried out in field conditions as shown in Figure 13. The aim is to verify the functionality of the technology in the field. The length of the test base is not significant because the precision of the shift measurements by radar interferometry technologies does not depend significantly on the distance to the monitored object but on the quality of the reflected signal.

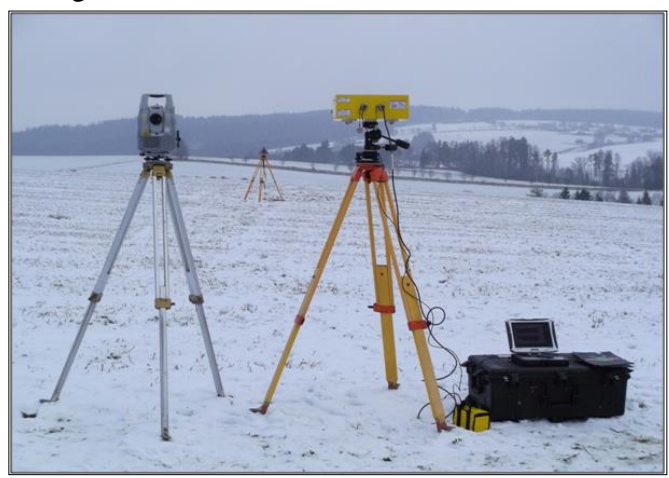

Figure 13. View of the test base in the LOS direction

In this particular case, a distance of $39 \mathrm{~m}$ was chosen. The IBIS$\mathrm{S}$ radar and the SOKKIA NET1AX total station (TS) were used. During the test, two $0.5 \mathrm{~mm}$ shifts in the direction from the radar and one $1 \mathrm{~mm}$ shift back to the radar were induced by a micrometer screw. Next, 5 shifts of $0.1 \mathrm{~mm}$ were made in the direction from the radar and one $0.5 \mathrm{~mm}$ shift back in the radar direction.

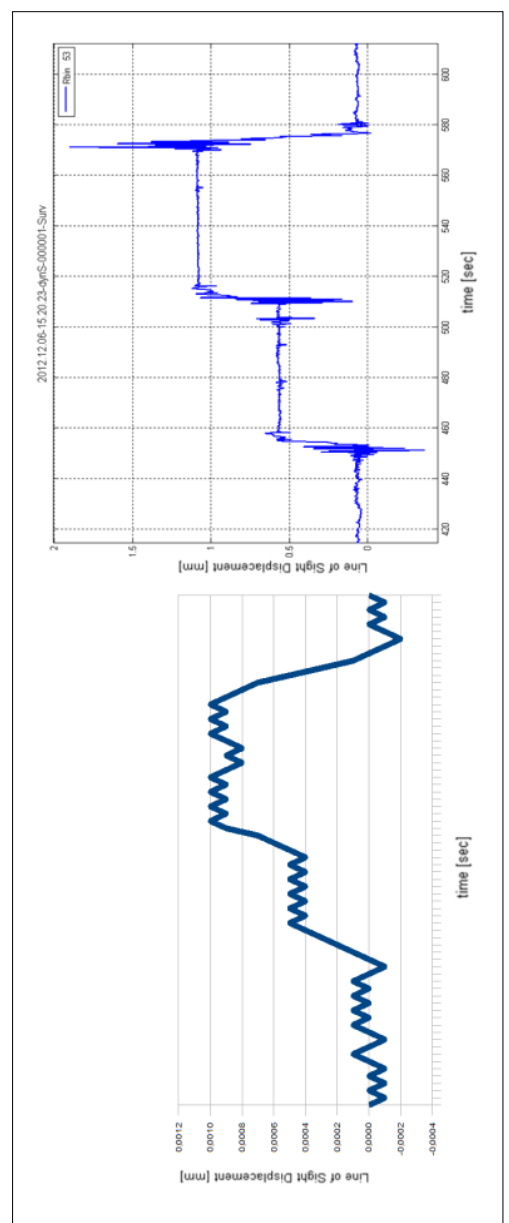

Figure 14. $0.5 \mathrm{~mm}$ shifts measured by TS (left) and radar (right)
The result of the first measurement is shown in Figure 14. On the left is a graph of shifts measured by the total station, in the right part there are shifts measured by radar interferometry technology. It is clear that the precision achieved by terrestrial radar interferometry technology surpasses the classical geodetic method, which is very significant.

The result of the measuring of $0.1 \mathrm{~mm}$ shifts is shown in Figure 15. The classical method of measuring such small shifts by the geodetic total station is completely failing, as is evident from the penultimate shift. Radar interferometry technology reliably measured shifts of $0.1 \mathrm{~mm}$ with a maximum scatter of $0.05 \mathrm{~mm}$.

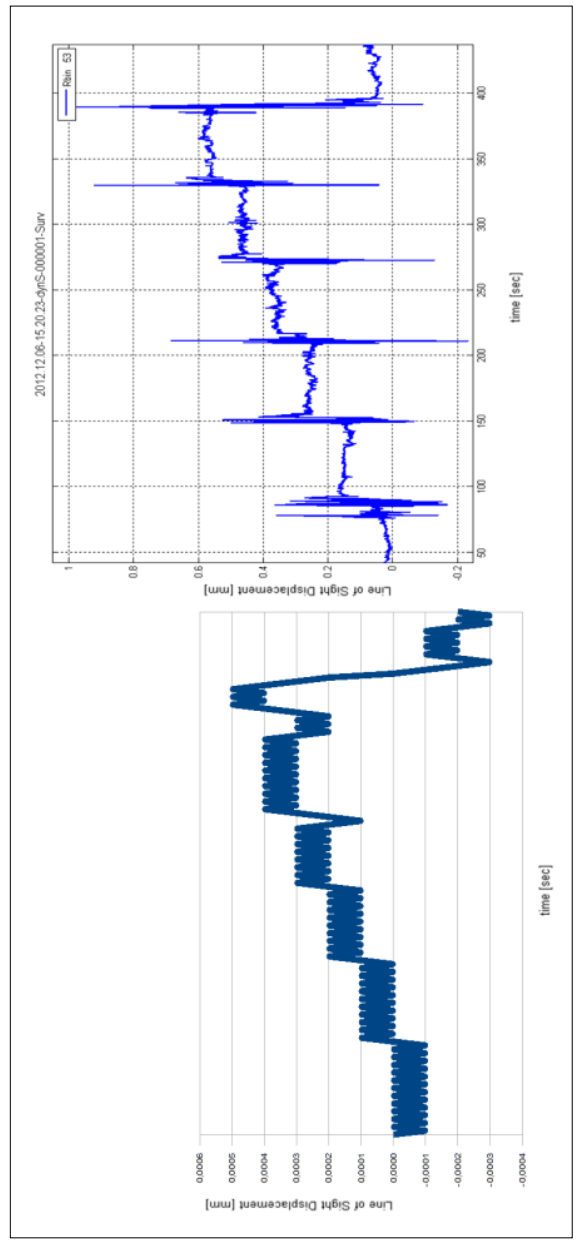

Figure $15.0 .1 \mathrm{~mm}$ shifts measured by TS (left) and radar (right)

Significant changes in shifts at the time they were induced by the micrometric screw are due to the touch of a hand on the micrometer screw. Greater variation of shifts in the time outside their realization by micrometer screw were caused by running through cars on a nearby road. The functionality of the technology has been verified in unfavourable field conditions. Testing has achieved the required precision, and it is therefore possible to state that this technology can be used for contactless determining and monitoring of shifts with a precision within the order of hundredths of mm with a maximum scatter of $0.05 \mathrm{~mm}$. 